\title{
Impact of the April-May SAM on Central Pacific Ocean sea temperature over the following three seasons
}

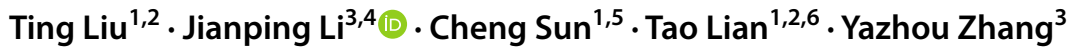

Received: 8 April 2020 / Accepted: 16 March 2021 / Published online: 27 March 2021

(c) The Author(s) 2021

\begin{abstract}
Although the impact of the extratropical Pacific signal on the El Niño-Southern Oscillation has attracted increasing concern, the impact of Southern Hemisphere Annular Mode (SAM)-related signals from outside the southern Pacific Basin on the equatorial sea temperature has received less attention. This study explores the lead correlation between the April-May (AM) SAM and central tropical Pacific sea temperature variability over the following three seasons. For the positive AM SAM case, the related simultaneous warm SST anomalies in the southeastern Indian Ocean favor significant regulation of vertical circulation in the Indian Ocean with anomalous ascending motion in the tropics. This can further enhance convection over the Marine Continent, which induces a significant horizontal Kelvin response and regulates the vertical Walker circulation. These two processes both result in the anomalous easterlies east of $130^{\circ} \mathrm{E}$ in the equatorial Pacific during AM. These easterly anomalies favor oceanic upwelling and eastward propagation of the cold water into the central Pacific. The cold water in turn amplifies the development of the easterly wind and further maintains the cold water into the boreal winter. The results presented here not only provide a possible link between extratropical climate variability in the Indian Ocean and climate variation in the equatorial Pacific, but also shed new light on the short-term prediction of tropical central Pacific sea temperature.
\end{abstract}

Keywords Southern Annular Mode $\cdot$ Air-sea interaction $\cdot$ Central Pacific Ocean

\section{Introduction}

Jianping Li

ljp@ouc.edu.cn

1 State Key Laboratory of Satellite Ocean Environment Dynamics, Second Institute of Oceanography, Ministry of Natural Resources, Hangzhou, China

2 Southern Marine Science and Engineering Guangdong Laboratory (Zhuhai), Zhuhai, China

3 Frontiers Science Center for Deep Ocean Multispheres and Earth System (FDOMES), Key Laboratory of Physical Oceanography, Institute for Advanced Ocean Studies, Ocean University of China, Qingdao 266100, China

4 Laboratory for Ocean Dynamics and Climate, Pilot Qingdao National Laboratory for Marine Science and Technology, Qingdao, China

5 College of Global Change and Earth System Science (GCESS), Beijing Normal University, Beijing, China

6 School of Oceanography, Shanghai Jiao Tong University, Shanghai, China
The tropics are generally considered to be the driving force of the global climate system, and the El Niño-Southern Oscillation (ENSO) is seen as the typical representation of the interannual tropical coupled air-sea interaction mode. The ENSO exerts a significant influence on climate around the Pacific region, and even globally, via its regulation of the meridional circulation and excitation of the planetary Rossby wave train. The ENSO-related Rossby wave has the potential to modulate the eddy-driven jet in the mid latitudes and further regulate the dominant atmospheric mode in the mid and high latitudes, over both interannual and long-term timescales (Alexander et al. 2002; Carril and Navarra 2001; Ding et al. 2012; Fogt and Bromwich 2006; Grassi et al. 2005; Kwok and Comiso 2002; Lau 1997; L'Heureux and Thompson 2006; Ribera and Mann 2003; Trenberth et al. 1998; Yuan and Martinson 2000). However, the extratropics can also influence the tropics via the atmospheric bridge and the oceanic tunnel (Liu and Yang 2003). The extratropical climate system and associated thermal forcing have the potential to modulate the tropical atmospheric circulation, 
such as the intertropical convergence zone (ITCZ; Kang et al. 2008), zonal winds (Gollan and Greatbatch 2015), meridional circulation (Liu et al. 2015, 2016; Zheng et al. 2015, 2018; Wu et al. 2009), and Rossby wave train (Liu et al. 2018, 2020).

Furthermore, observational and modeling studies have correlated the preceding extratropical air-sea signal in the Northern Hemisphere (NH) with the subsequent development of the ENSO, which allows the extratropical influence to propagate into the tropical Pacific Ocean via various air-sea interactions (Anderson 2004; Alexander et al. 2010; Boschat et al. 2013; Chang et al. 2007; Ding et al. 2015a, 2017; Li et al. 2014; Tseng et al., 2017; Vimont et al. 2001, 2003; Wang et al. 2012; Zhang et al. 2009a, b). This influence occurs because atmospheric fluctuations in the extratropical $\mathrm{NH}$ can imprint their signals onto the local sea surface temperature (SST) via air-sea interactions, and the corresponding SST footprints can persist for several seasons and regulate the atmospheric circulation. These processes have the potential to modulate zonal wind and SST anomalies through the wind-evaporation-SST feedback mechanism, which propagate extratropical influence into the tropics and further act as the precursor indicators to the subsequent ENSO events (Chiang and Vimont 2004; Chen et al. 2014; Vimont et al. 2001, 2003). Recently, there has been increasing evidence to show that extratropical Pacific climate variability in the Southern Hemisphere ( $\mathrm{SH}$ ) makes an indispensable contribution to the development of ENSO, including via the extratropical SST anomalies (Ding et al. 2015b; Yamazaki and Watanabe 2015; Zhang et al. 2014), the transverse cell in southern Australia (Hong and Jin 2014), and the SH annular mode (SAM; Zheng et al. 2017). The mechanism involved is driven mainly by the extratropical seasonal SST footprints (Zhang et al. 2014; Ding et al. 2015b), like its NH counterpart, or by the response of the meridional circulation to extratropical thermal forcing (Yamazaki and Watanabe 2015; Zheng et al. 2017), both of which have the potential to propagate the extratropical influence into the tropical Pacific and regulate zonal wind and SST anomalies in the same region.

Previous studies of the influence of the extratropical signal on tropical SST variability have focused mainly on the Pacific Ocean region, whether in the $\mathrm{NH}$ or SH. For example, the anomalous atmospheric or oceanic signal that originates from the extratropical Pacific Ocean and propagates into the equatorial region to regulate ENSO variability via an air-sea interaction process in the Pacific Basin. Several studies have also discussed the possible impact of the extratropical signal outside the Pacific on the tropical Pacific SST (Terray 2011; Levine et al. 2017). However, the possibility of a signal excited by the SAM outside the Pacific Basin that could affect the tropical Pacific has never been addressed. Given that the SAM is the leading atmospheric mode in the $\mathrm{SH}$ extratropics and involves hemispheric atmosphere-ocean-sea-ice system variability in the extratropical SH (Thompson et al. 2011), and the SAM signal can be transmitted into the $\mathrm{NH}$ via the Indian Ocean (Nan et al. 2009; Dou et al. 2017, 2020), tropical Pacific Ocean (Liu et al. 2018), and Atlantic Ocean (Wu et al. 2015). Therefore, we hypothesize that the propagation of the SAM signal into the tropics is also not limited only to the Pacific tunnel. The present study aims to identify the possible impact of the April-May (AM SAM) on sea temperature during the subsequent three seasons in the central Pacific Ocean and to investigate the corresponding contribution of air-sea interaction processes originating from the Indian Ocean. The outline of this paper is as follows. Detailed descriptions of the datasets and numerical model used are presented in Sect. 2. In the following section, we reveal the linkage between the preceding SAM and the subsequent sea temperature variability in the central Pacific Ocean. We then consider the corresponding mechanisms responsible for this relationship. A brief discussion and our concluding remarks are given in Sect. 4 .

\section{Datasets and model}

\subsection{Datasets}

For the present study, we extracted monthly mean atmospheric variables from the NCEP/NCAR reanalysis datasets (National Centers for Environmental Prediction-National Center for Atmospheric Research: https://psl.noaa.gov/data/ gridded/data.ncep.reanalysis.html), which have a resolution of $2.5^{\circ} \times 2.5^{\circ}$, including geopotential height (HGT), and the horizontal and vertical components of wind and surface heat flux. More details regarding the NCEP/NCAR data can be found in Kalnay et al. (1996). We also used the European Centre for Medium-Range Weather Forecasts (ECMWF) interim reanalysis (ERA-Interim; Dee et al. 2011: https:// apps.ecmwf.int/datasets/data/interim-land) and fifth generation ECMWF (ERA5; Hersbach et al. 2020: https://cds.clima te.copernicus.eu/cdsapp\#!/dataset/reanalysis-era5-singlelevels-monthly-means?tab=form) reanalysis to validate our results. The performance of these three datasets were basically consistent with each other. To represent the variability of convective activity, we used the monthly outgoing longwave radiation (OLR) data from the National Oceanic and Atmospheric Administration (NOAA) Interpolated Outgoing Longwave Radiation dataset (Liebmann and Smith 1996: https://psl.noaa.gov/data/gridded/data.interp_OLR.html) gridded at $2.5^{\circ} \times 2.5^{\circ}$. Monthly SST data were obtained from the NOAA ERSST V5 (Extended Reconstructed SST Version 5) dataset at a resolution of $2^{\circ} \times 2^{\circ}$ (Huang et al. 2017: https://psl.noaa.gov/data/gridded/data.noaa.ersst.v5. $\mathrm{html}$ ). We used subsurface sea temperature and circulation 
variables from the GODAS (NCEP Global Ocean Data Assimilation System) reanalysis dataset on a $0.33^{\circ} \times 1.0^{\circ}$ grid (Behringer et al. 1998: https://psl.noaa.gov/data/gridd ed/data.godas.html). Anomalies in the present study were identified by detrending the data, which removed the longterm monthly mean. Our study focused on the satellite era (1979-2018) to ensure reliable data quality in the SH.

We used two SAM indexes to represent the variability of the SAM: an index modified by Nan and Li (2003), which we refer to as "SAM_Nan\&Li" (see http://ljp.gcess.cn/dct/ page-/65609), and an index defined by Marshall (2003), which we refer to as "SAM_Marshall" (see http://www. nerc-bas.ac.uk/public/icd/gjma/newsam.1957.2007.txt). The SAM_Nan\&Li index is defined as the difference in the standardized zonal mean sea level pressure (SLP) between $40^{\circ} \mathrm{S}$ and $70^{\circ} \mathrm{S}$ calculated using the reanalysis data. The SAM_Marshall index is station-based and uses observational SLP from stations at mid and high latitudes in the SH to calculate substitution of the zonal mean SLP. These two SAM indexes are highly correlated with each other, with a correlation coefficient of 0.9 for AM. We used the Niño 3.4, Niño 3, and Niño 4 indexes obtained from NOAA's Climate Prediction Center to represent SST variability in the tropical Pacific, and also the Modoki index, calculated according to the definition of Ashok et al. (2007).

\subsection{Model}

We used an atmospheric general circulation model (AGCM) to investigate the atmospheric response to SAM-related SST variability. Control and sensitive experiments were performed based on the Community Atmosphere Model version 5.3 (CAM5; Hurrell et al. 2013), which is the atmospheric component of the Community Earth System Model (CESM). The horizontal resolution of CAM5 is approximately $2.8^{\circ} \times 2.8^{\circ}(\mathrm{T} 42)$, and the model has 30 vertical layers. We used the F component set to formulate the model. This model is widely used to explore the response of the atmospheric circulation to extratropical SST forcing (Zheng et al. 2015; Liu et al. 2015, 2018). The control experiment was forced by the climatological SST. CAM5 is able to simulate a climatic circulation that is broadly consistent with that seen in the observations. In the southeastern Indian Ocean (SEIO: $30-45^{\circ} \mathrm{S}, 70-115^{\circ} \mathrm{E}$ ), positive and negative SAMrelated SST anomaly patterns based on the AM SEIO SST index $>1$, and SEIO SST index $<-1$, were imposed onto the AM climatological SST, and we refer to these as the positive and negative sensitivity experiments, respectively. For both experiments, the model integration was run for 30 years, and our analysis was based on data from the last 20 years.

We used the Gill model (Gill 1980; Xing et al. 2014a) to investigate how the atmosphere responds to forcing by convective heating. The Gill model is based on a linear shallow water equation, and has been widely used to explain the response of the atmospheric circulation to the equatorial heating forcing (Wu and Zhou 2013; Xing et al. 2014b, 2016; Zhang et al. 2018; Li et al. 2019). Corresponding to the equatorial symmetric warm forcing, there is an easterly (westerly) wind to the east (west) of the heating center, and ascending motions occurs above the heating center (Gill 1980; Xing et al. 2014a).

\section{Results}

\subsection{Observational evidence}

Given that ENSO shows the largest seasonal variability during the December-January-February (DJF) period, we used various ENSO indexes to express the variability in DJF SST in the tropical Pacific Ocean. The observed lead-lag correlations between the DJF ENSO indexes and the 2-month running mean of the SAM index (SAMI) are shown in Fig. 1a. The most notable feature is that the preceding AM SAMI shows a significant negative correlation with the DJF Modoki index (red line), with a correlation coefficient (r) of -0.36 that is significant at the $95 \%$ confidence level (Fig. 1a). In addition, there is also a significant relationship between the DJF Niño 4 index (blue line) and the AM SAMI in Fig. 1a. Our correlation analysis of the SAMI and the various ENSO indexes indicate that the AM SAM is significantly related to the subsequent SST variability, and this connection occurs mainly in the tropical central Pacific Ocean rather than the eastern Pacific Ocean. The lead-lag correlation between the DJF Modoki index and the different SAM indexes (Fig. 1b) also confirms the above mentioned negative relationship between the AM SAM and the subsequent DJF Modoki, and further indicates that this relationship is independent of the choice of SAMI and is robust.

We note that there is also a significant negative correlation for the case where the DJF Modoki leads the AM SAM $(\mathrm{r}=-0.40$, significant at the $99 \%$ confidence level), which indicates that the AM SAM and DJF Modoki may statistically influence each other (such as: preceding DJF Modoki leads to AM SAM leads to following DJF Modoki), and suggests that the relationship between the AM SAM and the following DJF Modoki may contain the influence of the preceding DJF Modoki. To investigate this, we used partial correlation analysis to remove the impact of the preceding DJF Modoki signal. The results showed that AM SAMI was still significantly negatively correlated with the following DJF Modoki index (Fig. 2a). In addition, running correlation analysis further indicated that this relationship remained stable and strengthened after the 1970s (Fig. 2b).

Furthermore, the preceding AM zonal averaged HGT in the SH is also significantly correlated with the DJF Modoki 

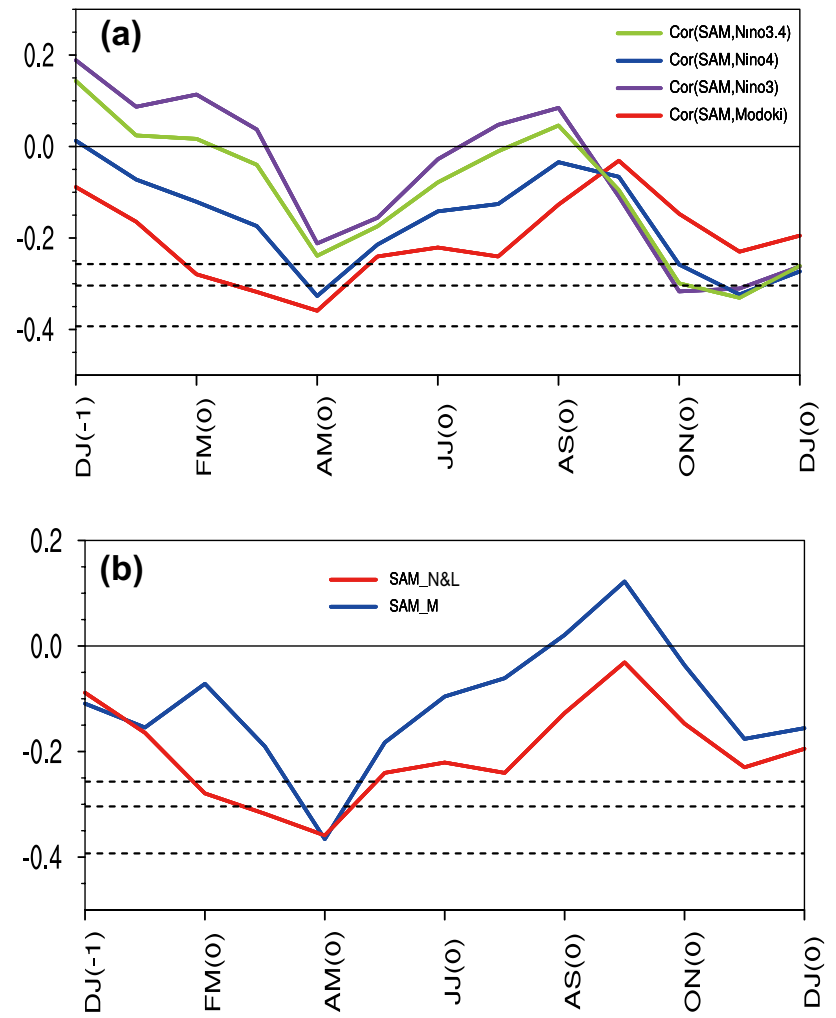

Fig. 1 a Lead-lag correlation between the SAM_Nan\&Li index and the DJF ENSO index. The red, blue, purple, and green lines indicate the Modoki, Niño4, Niño 3, and Niño 3.4 indexes, respectively. b Lead-lag correlation between the different SAM indexes and DJF Modoki index. The red and blue lines indicate the SAM_Nan\&Li and SAM_Marshall indexes, respectively. The dashed black lines indicate the $90 \%, 95 \%$, and $99 \%$ confidence levels for Student's $t$ test. DJ is defined as the December of this the present year and January of the next following year. "DJ (-1)" indicates the boreal winter of preceding year, and the "DJ (0)" indicates the boreal winter of present year

index (Fig. 3a), and the distinctive feature is a negative SAM pattern that involves a significant seesaw HGT structure between the mid and high latitudes in the SH. This negative SAM pattern is also significant after removing the preceding DJF Modoki signal (Fig. 3b). This provides further evidence that the positive (negative) preceding AM SAM frequently favors the following anomalous cold (warm) water over the tropical central Pacific Ocean during DJF, and that this relationship is robust. In the next section, we investigate the possible physical mechanism that drives this relationship.

\subsection{A possible physical mechanism}

\subsubsection{SST anomalies corresponding to the AM SAM and DJF Modoki}

Here, we are interested in how the preceding SAM persists into the following DJF season and exerts an influence on the tropical central Pacific Ocean. As the persistence
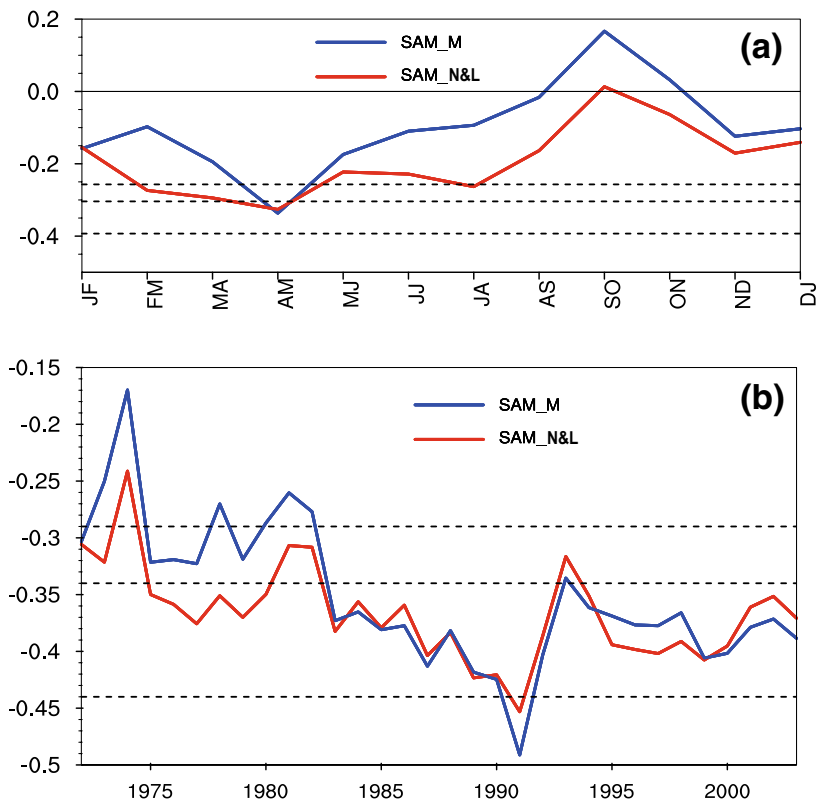

Fig. 2 a Lead-lag correlation between the different SAM indexes and the DJF Modoki index without the preceding DJF Modoki signal. b Running correlation between the different SAM indexes and the DJF Modoki index using a 31-year moving window. The red and blue lines are the SAM_Nan\&Li and SAM_Marshall indexes, respectively. The dashed black lines indicate the $90 \%, 95 \%$, and $99 \%$ confidence levels for Student's $t$ test
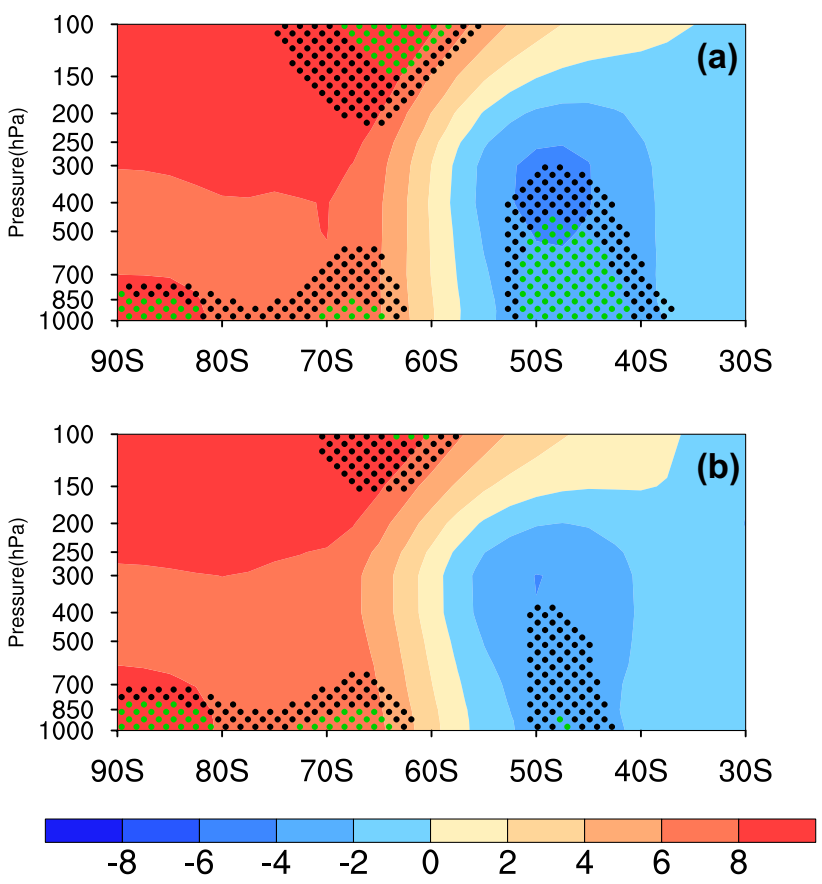

Fig. 3 Regression maps between the DJF Modoki index and AM zonal mean geopotential height in the $\mathrm{SH} \mathbf{a}$ before and $\mathbf{b}$ after removing the preceding DJF Modoki signal in NCEP reanalysis. The black and green stippled areas indicate regression coefficients significant at the $90 \%$ and $95 \%$ confidence levels, respectively 
of the atmospheric signal itself is of short duration, we take into consideration the underlying ocean, which has the potential to be imprinted by the SAM-related surface wind via the modulation of the air-sea heat exchange and inducing the oceanic meridional Ekman transport (Thompson and Wallace 2000a, b; Trenberth et al. 2005; Sen Gupta and England 2006; Sallée et al. 2010; Yeo and Kim 2015; Dou and Wu 2018). Figure 4 presents maps of the regression coefficients of the AM SST anomalies based on the following DJF Modoki index (Fig. 4a) and the AM SAMI (Fig. 4b). Corresponding to the positive DJF Modoki case, there are notable cold SST anomalies in the SEIO (green box in Fig. 4) during AM (Fig. 4a). By contrast, there are significant positive SST anomalies correlated with the positive AM SAM phase in the same region (Fig. 4b). These anomalous SST patterns are also significant even after removing the preceding DJF Modoki signal (Fig. 4c, d). Unless otherwise specified, in the following analysis, all results exclude the influence of the preceding DJF Modoki signal. The out-of-phase nature of the anomalous SST patterns related to the DJF Modoki and the AM SAM also accords with the negative relationship between the DJF Modoki and the AM SAM. We therefore infer that anomalous SSTs in the SEIO help to establish the relationship between the AM SAM and the following DJF SST variability of the tropical central Pacific Ocean.
Moreover, the SST in the SEIO has also been interpreted as an "ocean bridge" that propagates the influence of the SAM into the $\mathrm{NH}$, such as the East Asian monsoon region (Nan et al. 2009; Dou et al. 2020) and Indian monsoon region (Dou et al. 2017). The positive AM SAM is typically accompanied by the eastern zonal wind around $30-40^{\circ} \mathrm{S}$ over the southern Indian Ocean (Fig. 5a), which can not only induce the southward Ekman transport of warm water (Fig. 5b), but can also regulate weaker local wind speeds that influence the rate of air-sea heat release. Corresponding to the positive AM SAM, there is significant positive downward sensible heat flux in the extratropical SEIO, and negative sensible and latent heat flux in the extratropical southwestern Indian Ocean (SWIO). The cooperation between the Ekman transport and sensible heat flux variability contributes to the significantly warmer SST anomalies in the SEIO region. The significant positive Ekman transport and negative sensible and latent heat fluxes cancel each other out in the SWIO. Therefore, the significant SST anomalies exist only in the SEIO region. When the SAM is in its negative phase, the situation is reversed. Thus, the above two SAMrelated dynamic and thermodynamic processes can regulate SST variability in the SEIO.

Next, we defined the standardized regional mean SST anomalies over the SEIO as the SEIO SST index (SEIOSI) to quantify SST variability in this region. The SEIOSI is (a)

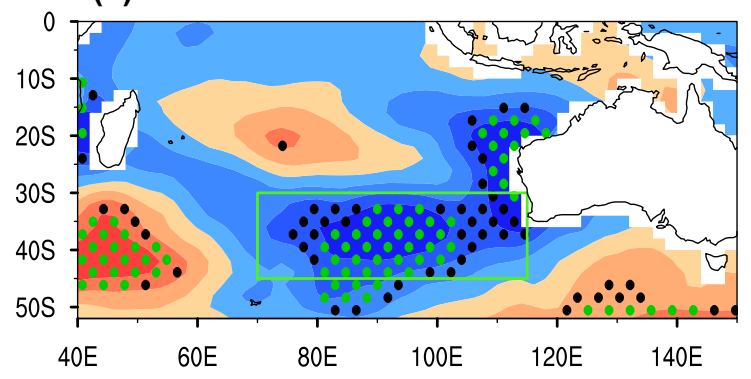

(c)

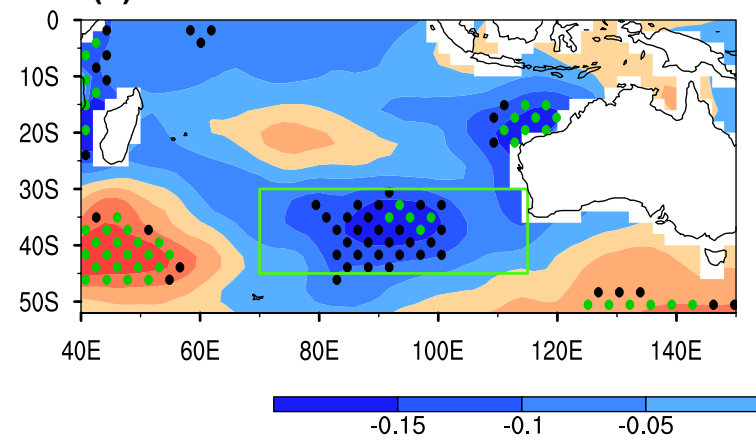

(b)

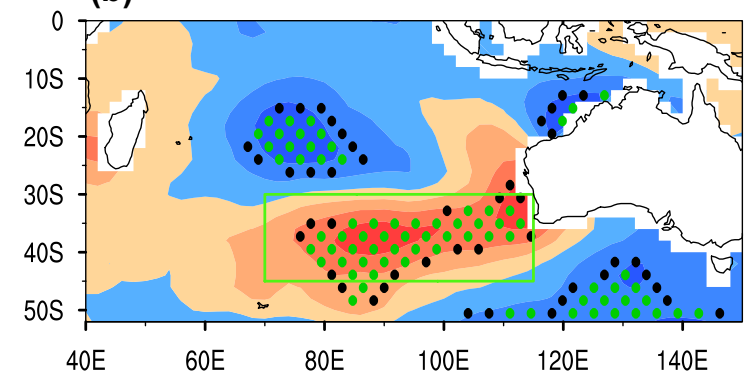

(d)

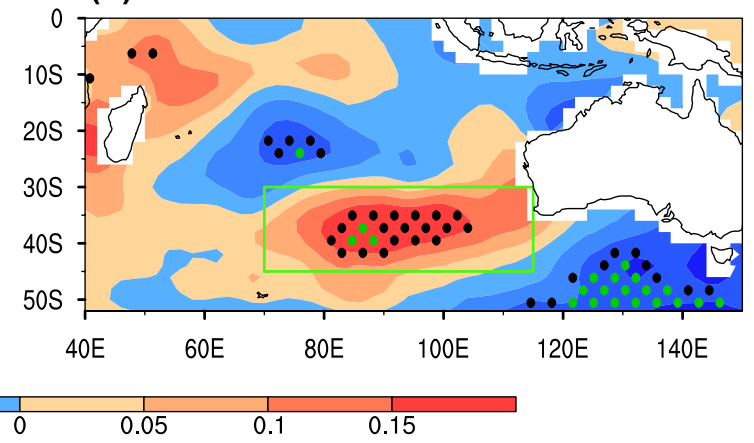

Fig. 4 Regression maps of AM SST anomalies with the a following DJF Modoki index, and b AM SAM_Nan\&Li index. c, d Correspond to $\mathbf{a}$ and $\mathbf{b}$, but without the preceding DJF Modoki signal. The black and green stippled areas indicate regression coefficients significant at the $90 \%$ and $95 \%$ confidence levels, respectively. The green boxes indicate the southeastern Indian Ocean 
(a)

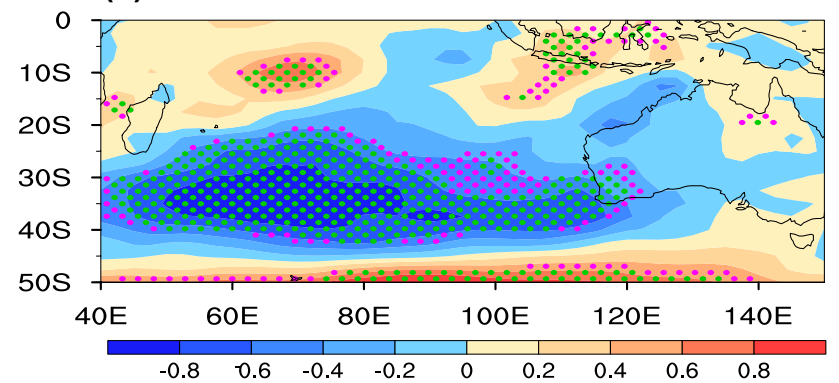

(b)

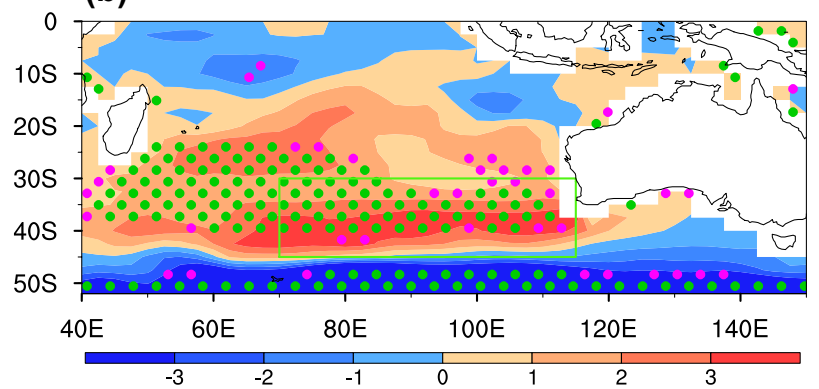

(c)

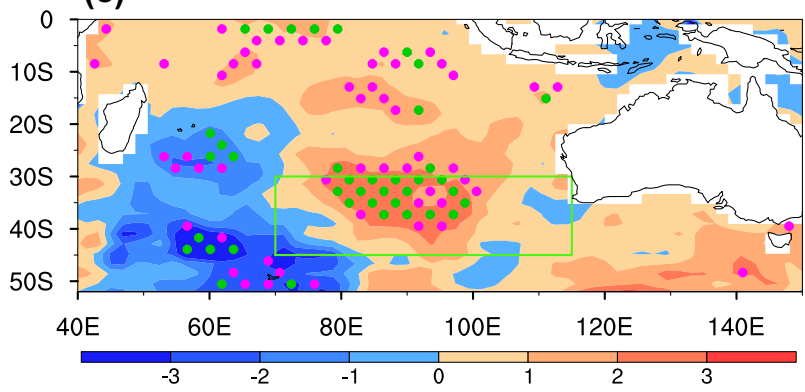

(d)

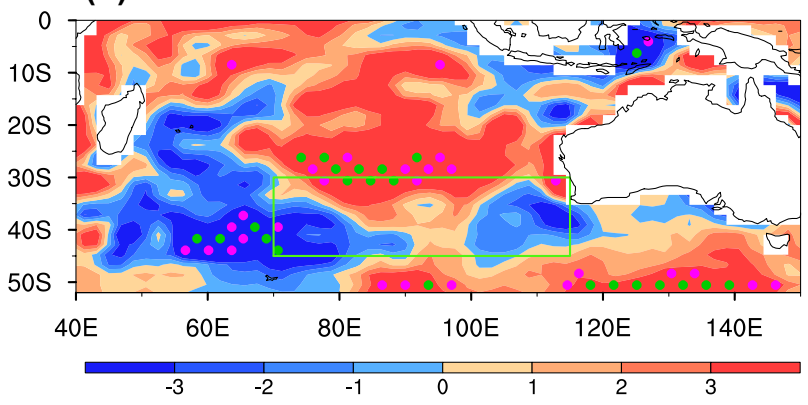

Fig. 5 Partial regression maps of AM a surface zonal wind, b Ekman heat flux, $\mathbf{c}$ sensible heat flux and $\mathbf{d}$ latent heat flux based on the AM SAMI after removing the previous DJF Modoki signal in NCEP reanalysis. The pink and green stippled areas indicate regression coefficients significant at the $90 \%$ and $95 \%$ confidence levels, respectively. The green boxes indicate the region of southeastern Indian Ocean

significantly positively correlated with the AM SAMI $(r=0.51$, significant at the $99 \%$ confidence level), suggesting that the positive AM SAM may usually be associated with the simultaneous anomalous warm SST over the SEIO. In addition, the AM SEIOSI exhibits a negative relationship (a)

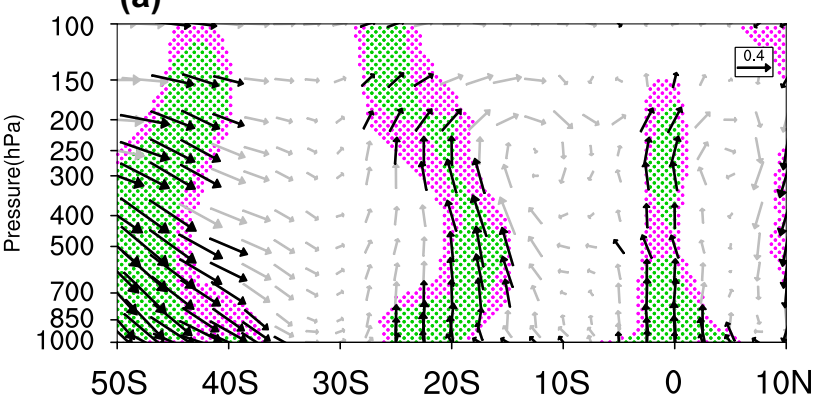

(b)

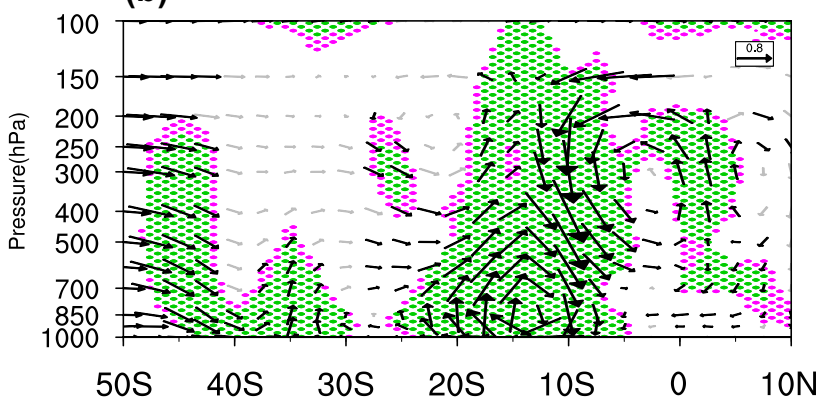

Fig. 6 a Partial regression map of the AM vertical velocity and meridional wind averaged between $90-120^{\circ} \mathrm{E}$ based on the AM SEIOSI after removing the preceding DJF Modoki signal in NCEP reanalysis. $\mathbf{b}$ The composite difference of the simulated response of AM vertical velocity and meridional wind averaged between $90-120^{\circ} \mathrm{E}$ between the positive and negative sensitivity experiment in CAM5. The pink and green stippled areas indicate vertical velocity significant at the $90 \%$ and $95 \%$ confidence levels, respectively. The black vectors indicate significance at the $90 \%$ confidence level

with the DJF Modoki index, with a correlation coefficient of -0.38 (significant at the $95 \%$ confidence level). The inverse correlation of the AM SEIOSI with AM SAMI and DJF Modoki further indicates that SST in the SEIO may become a potential bridge to connect the relationship between the AM SAM and the DJF Modoki.

\subsubsection{Atmospheric response to anomalous SST in the SEIO}

Here, we consider how SST anomalies associated with AM SAM in the SEIO can affect the subsequent tropical central Pacific variability. The SST anomalies in the SEIO can change the meridional gradient of SST in the Indian Ocean, which have the potential to regulate the meridional circulation (Marshall and Connolley 2006; Chen et al. 2010; Zheng et al. 2015, 2018). Firstly, we investigated the corresponding response of the atmospheric meridional circulation. When the SEIO SST anomalies are in a positive phase, there is significant anomalous downward motion to the south of $45^{\circ} \mathrm{S}$ and upward movement around $20^{\circ} \mathrm{S}$ and $0^{\circ}$, which correspond to the adjustments in the meridional circulation (Fig. 6a). The response of the meridional circulation to the 
anomalous SST in the SEIO was also basically reproduced in our sensitivity experiments using the CAM5 model. The composite differences in the meridional circulation between the positive and negative experiments are presented in Fig. 6b. Corresponding to the warmer AM SST anomalies forcing in the SEIO, there is a significant anomalous sinking movement around $40^{\circ} \mathrm{S}$, and ascending motion around $20^{\circ} \mathrm{S}$ and above $500 \mathrm{hPa}$ around $0^{\circ}$. This scenario is broadly consistent with the observed anomalous vertical movement response. However, the model overestimates the downward motion near $10^{\circ} \mathrm{S}$ and also the upward motion south of $30^{\circ} \mathrm{S}$, which are insignificant in the observations.

(a)

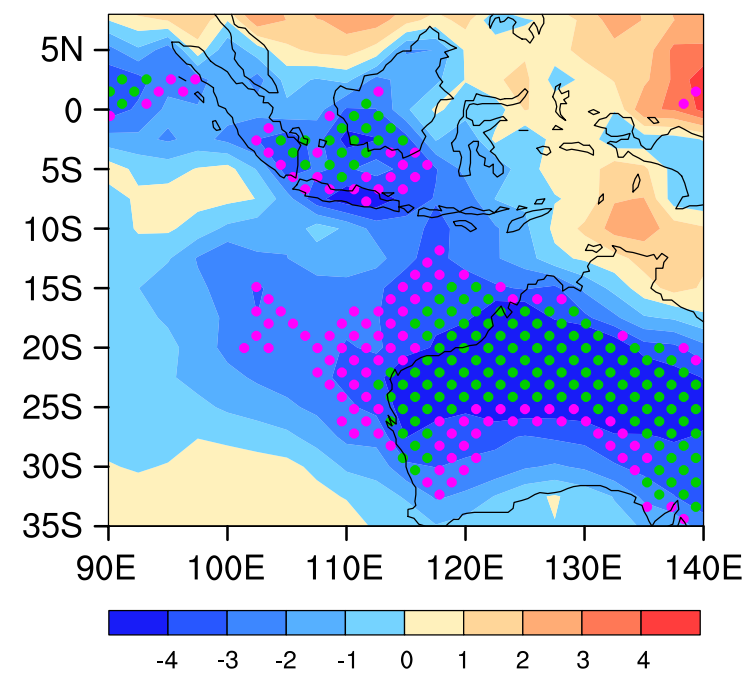

(c)

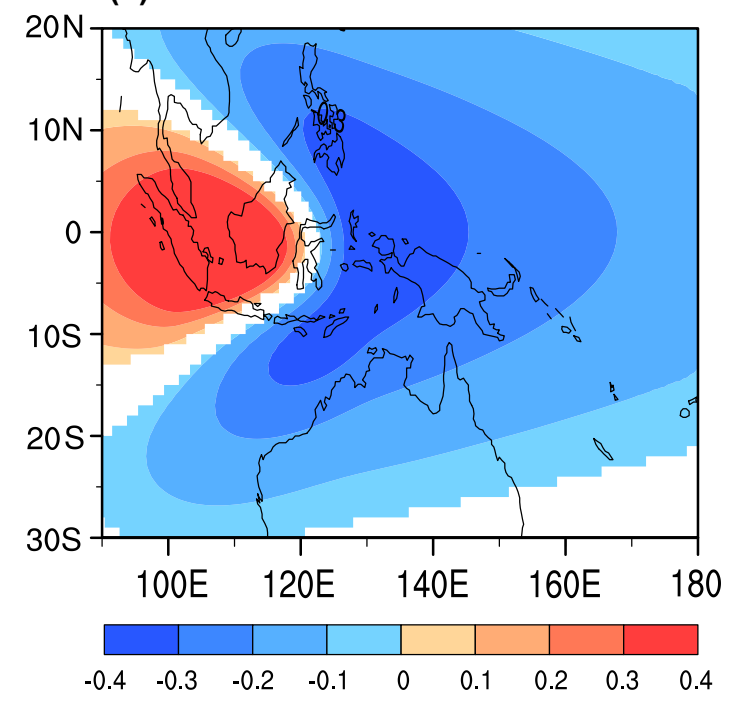

Fig. 7 a Partial regression map of AM OLR based on the AM SEIOSI after removing the preceding DJF Modoki signal. The pink and green stippled areas indicate regression coefficients significant at the $90 \%$ and $95 \%$ confidence levels, respectively. b The ideal heating
In addition, the significant upward motion in the middle and lower troposphere around $0^{\circ}$ are underestimated in the model. A possible explanation for this is that the model overestimates (underestimates) the variation of vertical movement in the $10^{\circ} \mathrm{S}$ and $30^{\circ} \mathrm{S}\left(0^{\circ}\right)$ in the control run when compared with the observations. Overall, the model simulation approximately captures the response of the observed meridional circulation and the associated anomalous upward motion in the tropical region during AM.

The anomalous upward motion in the tropics $\left(90-120^{\circ} \mathrm{E}\right)$ indicates increasing tropical convection with negative OLR anomalies (Fig. 7a) over the Maritime Continent. We

(b)

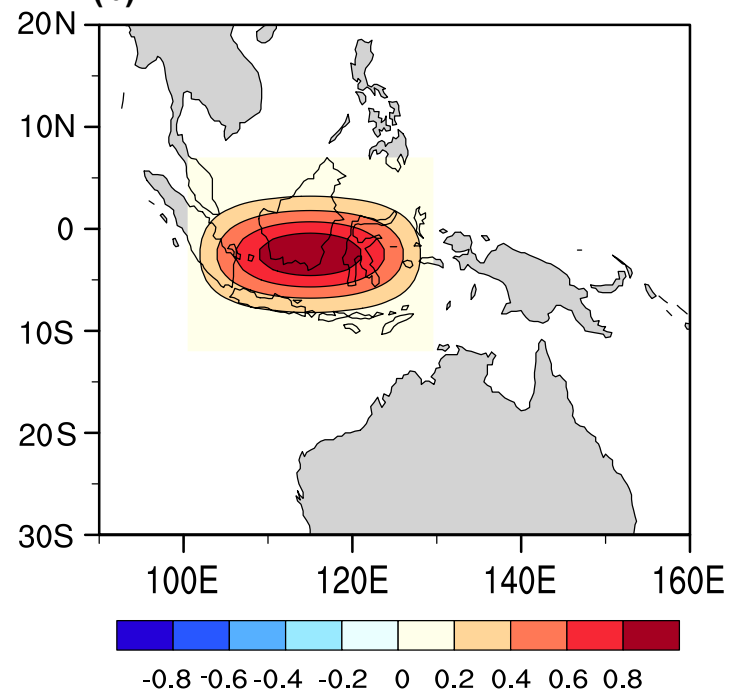

(d)

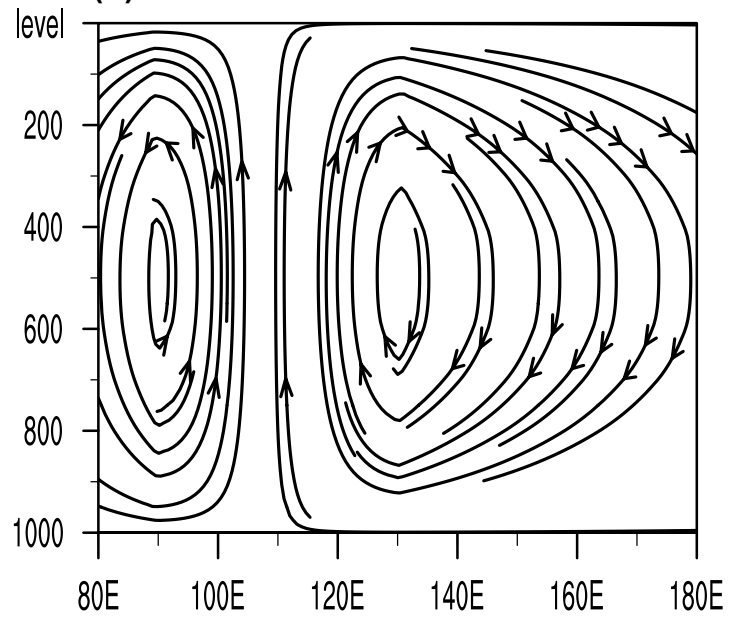

forcing in the Gill model. c The response of zonal wind to the heating forcing in the Gill model. d The response of vertical circulation to the heating forcing in the Gill model 
used the Gill model (1980) to investigate the atmospheric response to this convective heating. The related heating forcing (Fig. 7b) can result in the horizontal Kelvin response and anomalous vertical clockwise circulation with the anomalous easterlies (westerlies) to the east (west) of the heating source center (Fig. 7c) and the upward (downward) branch above the heating source center (in the central Pacific Ocean, Fig. 7d). Therefore, there is an observational anomalous Walker circulation response as shown in Fig. 8. The observations and the model results both indicate that anomalous SST in the SEIO can induce anomalous upward motion in the tropics, which results in the intense convection over the Maritime Continent and in turn regulates the Walker circulation and induces the Kelvin response to the east of $130^{\circ} \mathrm{E}$ during AM. The associated easterly wind anomalies have the potential to maintain the development of the following anomalous zonal wind and sea temperature in the equatorial central Pacific region via tropical air-sea interaction. These relationships will be investigated in the next section.

\subsubsection{Influence of zonal wind on sea temperature in the tropical central Pacific Ocean}

Zonal wind anomalies can make a vital contribution to the variability in sea temperature anomalies within equatorial regions (Bjerknes 1969). Figure 9 presents the evolution of the anomalous surface wind, sea temperature, and ocean currents associated with the AM SEIO SST. In particular, there is an anomalous easterly wind at the equator between $130^{\circ} \mathrm{E}$ and $150^{\circ}$ E (Fig. 9a) during AM. This anomalous easterly wind (vector in Fig. 9a) to the east of $140^{\circ} \mathrm{E}$ enhances the easterly wind speed in the climatic trade winds region (shading in Fig. 9a), which can induce significant upward motion that moves cold water into the upper ocean (Fig. 9f). The corresponding anomalous eastward oceanic current can propagate

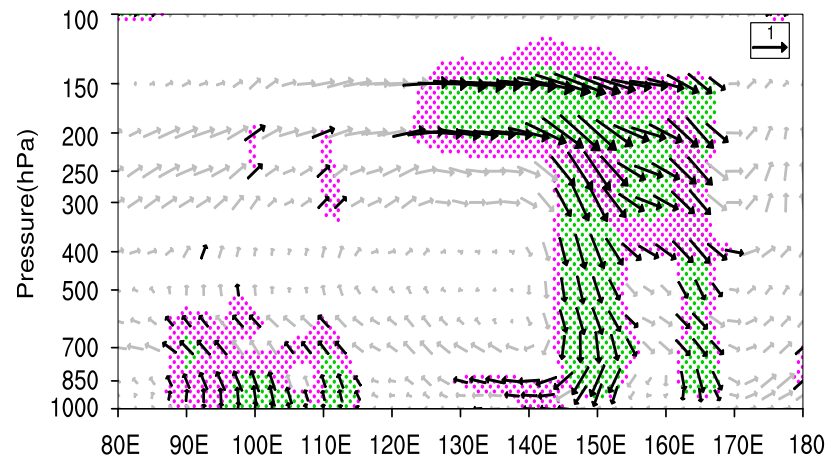

Fig. 8 Partial regression map of the AM vertical velocity and zonal wind averaged between $5^{\circ} \mathrm{S}-5^{\circ} \mathrm{N}$ based on the AM SEIOSI after removing the preceding DJF Modoki signal in NCEP reanalysis. The pink and green stippled areas indicate zonal and vertical wind significant at the $90 \%$ and $95 \%$ confidence levels, respectively. The black vectors indicate significance at the $90 \%$ confidence level this cold water into the central Pacific Ocean $\left(160-180^{\circ}\right.$ E). These upward and eastward motions result in significant cold water at depths of 100-150 $\mathrm{m}$ in the central Pacific Ocean during AM. The upward movement of cold water can reach the surface ocean during June-July (JJ) (Fig. 9g), and the anomalous easterly zonal wind develops further to the east and outside the equatorial region (Fig. 9b). In the August-September (AS) and October-November (ON), the surface anomalous easterly winds and cold water develop further (Fig. 9c, d, h, i). Corresponding to the oceanic ascending motion around $140-160^{\circ} \mathrm{E}$, there is downward motion to the east of $180^{\circ} \mathrm{E}$, which can lead to the downward and westward transport of the cold water. Therefore, the significant area of cold water exists mainly around $160-200^{\circ} \mathrm{E}$. The maximum upward motion anomalies in the central Pacific Ocean, which correspond to one standard deviation of SEIOSI, can reach the same magnitude as the climatic vertical velocity (i.e., $10^{-6} \mathrm{~m} / \mathrm{s}$ ), and this can generate an average increase of $12.8 \%$ in Ekman upwelling between AM and December-January (DJ). Furthermore, the maximum cold sea temperature anomaly can reach $-0.48 \mathrm{~K}$ in the central Pacific Ocean.

In addition, the speed of the anomalous AM easterly wind decreases the wind speed around $130-140^{\circ} \mathrm{E}$ (the climatic westerly wind region; shading in Fig. 9a), and this corresponds to the weak warm water above $50 \mathrm{~m}$ west of $130^{\circ} \mathrm{E}$ (Fig. 9f). The climatic surface westerly wind expands eastward with time, and the anomalous easterly wind in the west Pacific Ocean further decreases the wind speed (Fig. 9b-e), resulting in the downward movement of warm water and its eastward propagation into the central Pacific Ocean from JJ to DJ (Fig. $9 g-j$ ), which finally warms the cold sea temperature in the central Pacific Ocean during DJ. In brief, the anomalous AM easterly wind associated with the AM SST anomalies to the east of $140^{\circ} \mathrm{E}$ can enhance the zonal wind speed over the tropical central Pacific Ocean, where it is controlled by the prevailing easterly trade winds. The increased wind speed favors oceanic upwelling of cold water and its eastward propagation into the central Pacific Ocean. This cold water can reach the surface during JJ and trigger variability in the overlying atmosphere, maintain the following easterly zonal wind anomalies, and further induce subsurface upward motion and develop the cold water anomalies. The anomalous easterlies to the east of $140^{\circ} \mathrm{E}$ reduce the wind speed and result in the downward and eastward transport of warm water. Taken together, these coupled air-sea processes result in the development, and then decay, of the cold water in the central Pacific Ocean between $\mathrm{AM}$ and DJ. 
(a) AM

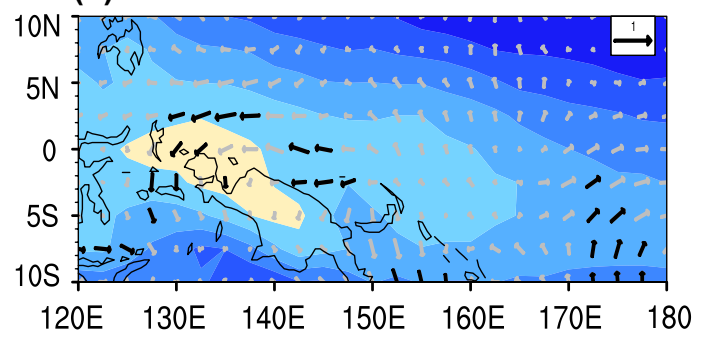

(b) $\mathrm{JJ}$

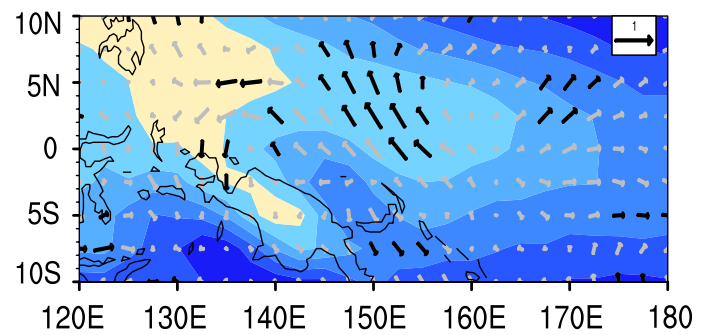

(c) AS

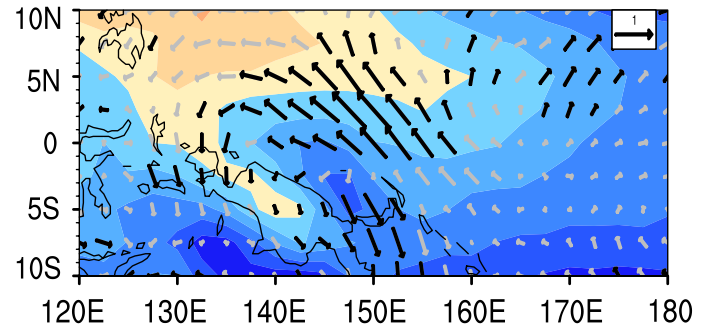

(d) ON

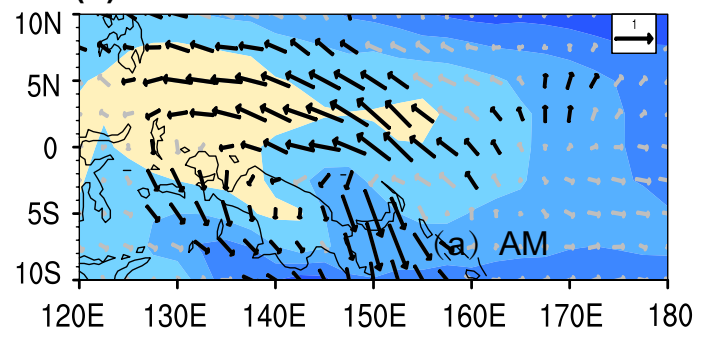

(e) DJ

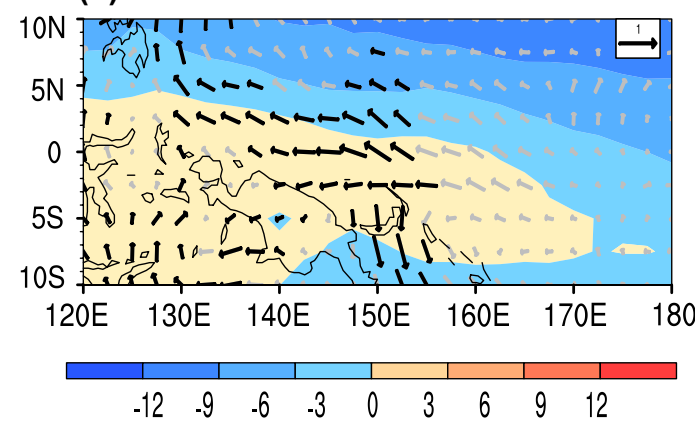

Fig. 9 Partial regression maps of the a-e surface wind (vector) and climatic zonal wind (shading) and $\mathbf{f}-\mathbf{j}$ sea temperature (shading) and oceanic current (vector) averaged between $10^{\circ} \mathrm{S}-10^{\circ} \mathrm{N}$ based on the AM SEIOSI from AM to DJ after removing the preceding DJF

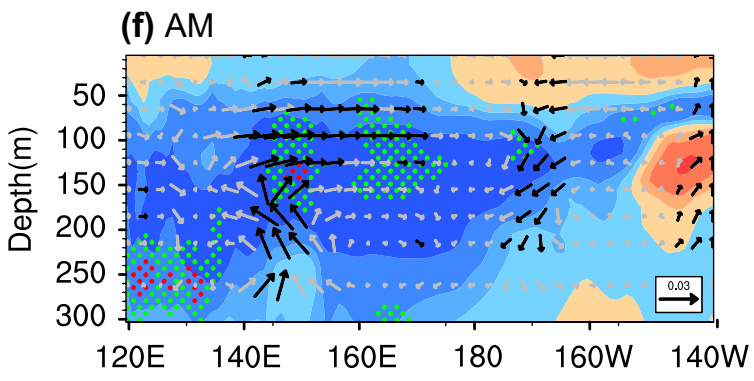

(g) $\mathrm{JJ}$

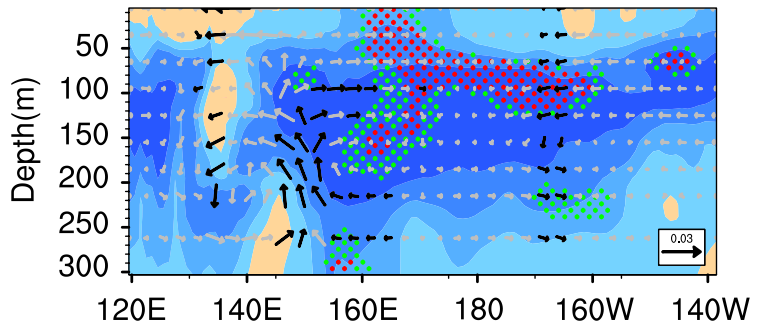

(h) AS

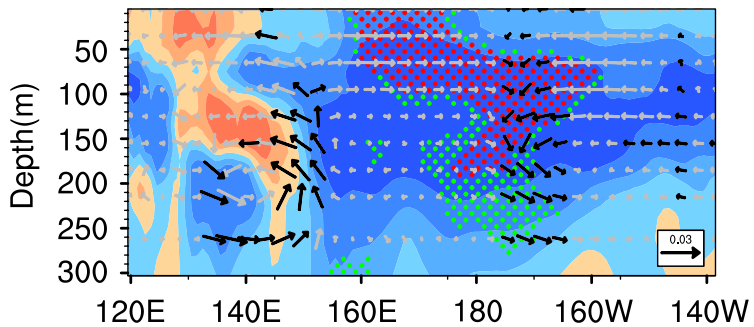

(i) $\mathrm{ON}$
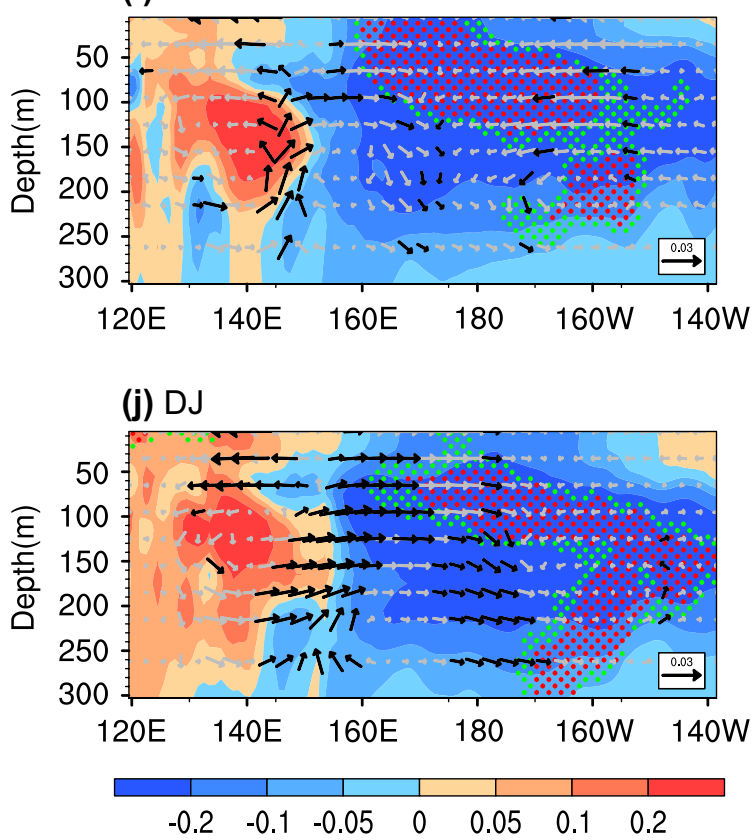

Modoki signal. The pink and green stippled areas indicate regression coefficients significant at the $90 \%$ and $95 \%$ confidence levels, respectively. The black vectors indicate significance at the $90 \%$ confidence level 
Fig. 10 Schematic diagram showing the influence of the AM SAM related SST (red box) in SEIO on the following sea temperature (blue boxes) in the central Pacific Ocean from AM to DJ. The green arrows indicate the vertical circulation. The yellow arrows indicate the surface wind. The blue arrows indicate oceanic currents

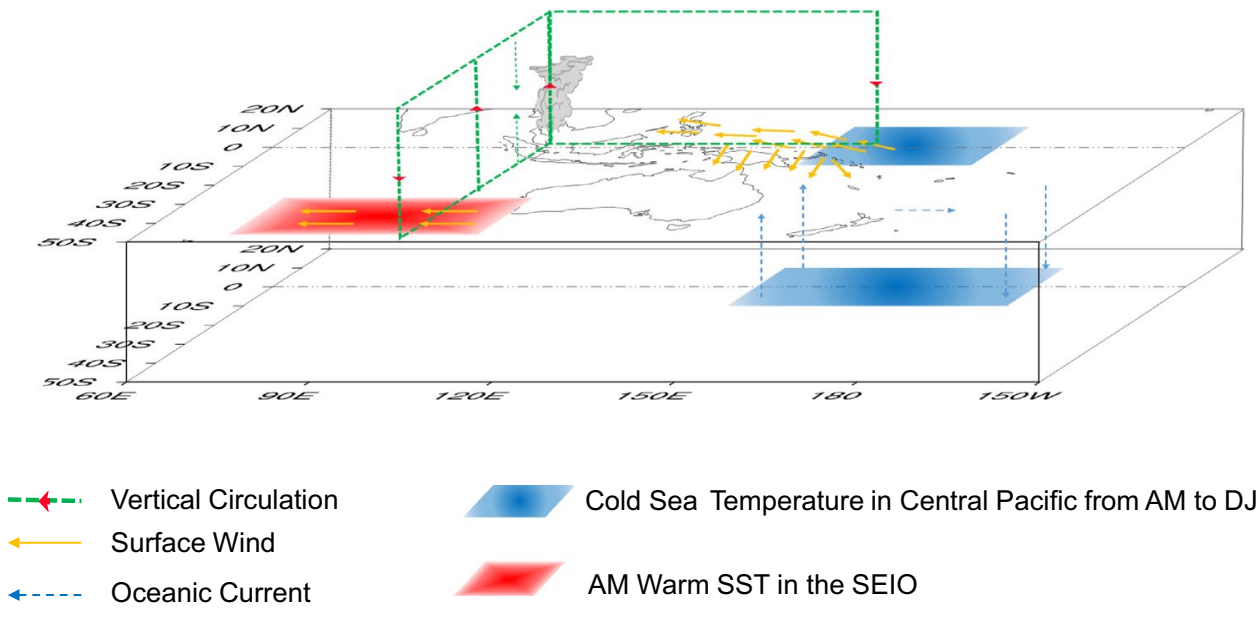

\section{Summary and discussion}

The influence of the SH extratropical atmospheric signal on the following tropical SST variability has attracted increasing research attention, which has focused mainly on the air-sea interaction processes in the Pacific Ocean region. In this study, we explored the possible impact of the preceding AM SAM on the following sea temperature variability in the central Pacific Ocean from the Indian Ocean perspective. The positive AM SAM favors cold sea water in the tropical central Pacific Ocean over the period between AM and DJ. This relationship is robust when the influences of the preceding ENSO signal and the long-term trend are excluded.

The possible physical mechanisms underlying this significant negative relationship involve the following coupled air-sea processes. The positive AM SAM-related surface wind favors the simultaneous warm SST in the SEIO via its influence on the oceanic Ekman transport and the exchange of sensible and latent heat fluxes. The anomalously warmer SST changes the meridional circulation in the Indian Ocean and causes ascending motion anomalies in the tropics. This can result in enhanced convection over the Marine Continent. The associated heating forces the Kelvin response and anomalous clockwise zonal-vertical circulation in the tropical region, resulting in downward motion around $145-165^{\circ} \mathrm{E}$ and easterly wind anomalies east of $130^{\circ} \mathrm{E}$ during AM. The anomalous easterlies to the east of $140^{\circ} \mathrm{E}$ tend to enhance the prevailing easterly trade winds, and induce the oceanic upwelling and eastward transport of cold water into the central Pacific Ocean. This cold water in turn amplifies the development of the easterly wind and further maintains the cold water into the boreal winter. This process is summarized in the schematic diagram in Fig. 10. Therefore, the anomalous SST in the SEIO and the associated air-sea interactions function as an indispensable bridge to promote the extratropical atmospheric signal-SAM-into the deep tropical region and regulate tropical sea temperature variability. Note that the relationship described in this study is significant at the $90 \%$ level after removing the previous DJF Modoki signal. This indicates that relationship between the AM SAM and DJF Modoki perhaps feeds back from the prior DJF Modoki, and that this helps to strengthen the overall relationship.

The lead correlation between the AM SAM and the following Modoki implies that the preceding SAM has the potential to affect subsequent tropical variability, and this influence is mainly observed in the central Pacific Ocean. This relationship may provide an additional source of predictability for the tropical central Pacific Ocean sea temperature from the perspective of the extratropical Indian Ocean. Combined with previous studies that have also emphasized the inferred contribution of the extratropical signal within the Pacific Basin to climatic variability in the deep tropical eastern Pacific, we conclude that assimilating the extratropical signal into coupled models should improve the prediction skill for the tropical Pacific climate. Further research will be needed if the various extratropical influences are to be incorporated into future predictions of the tropical Pacific climate.

Acknowledgements This study was jointly supported by the National Natural Science Foundation of China (41690124, 41790474, 41705049 and 41690120 ), the National Key R\&D Program of China (2017YFA0604202, 2016YFA0601801), the Zhejiang Provincial Natural Science Foundation of China (LR19D060001), Indo-Pacific Ocean Variability and Air-Sea Interaction (IPOVAI grant no. GASI-01WPAC-STspr), the Fundamental Research Funds for the central Universities (201962009), and the Shandong Natural Science Foundation Project, ZR2019ZD12.

Open Access This article is licensed under a Creative Commons Attribution 4.0 International License, which permits use, sharing, adaptation, distribution and reproduction in any medium or format, as long as you give appropriate credit to the original author(s) and the source, provide a link to the Creative Commons licence, and indicate if changes were made. The images or other third party material in this article are included in the article's Creative Commons licence, unless indicated otherwise in a credit line to the material. If material is not included in 
the article's Creative Commons licence and your intended use is not permitted by statutory regulation or exceeds the permitted use, you will need to obtain permission directly from the copyright holder. To view a copy of this licence, visit http://creativecommons.org/licenses/by/4.0/.

\section{References}

Alexander MA, Bladé I, Newman M, Lanzante JR, Lau NC, Scott JD (2002) The atmospheric bridge: the influence of ENSO teleconnections on air-sea interaction over the global oceans. J Clim 15:2205-2231

Alexander MA, Vimont DJ, Chang P, Scott JD (2010) The impact of extratropical atmospheric variability on ENSO: testing the seasonal footprinting mechanism using coupled model experiments. J Clim 23:2885-2901

Anderson BT (2004) Investigation of a large-scale mode of oceanatmosphere variability and its relation to tropical Pacific sea surface temperature anomalies. J Clim 17(20):4089-4098

Ashok K, Behera SK, Rao SA, Weng HY, Yamagata T (2007) El Niño Modoki and its possible teleconnection. J Geophys Res 112:C11007

Behringer DW, Ji M, Leetmaa A (1998) An improved coupled model for ENSO prediction and implications for ocean initialization. Part I: the ocean data assimilation system. Mon Weather Rev 126:1013-1021

Bjerknes J (1969) Atmospheric teleconnections from the equatorial Pacific. Mon Weather Rev 97:163-172

Boschat G, Terray P, Masson S (2013) Extratropical forcing of ENSO. Geophys Res Lett 40:1605-1611

Carril AF, Navarra A (2001) Low-frequency variability of the Antarctic circumpolar wave. Geophys Res Lett 28:4623-4626

Chang P, Zhang L, Saravanan R, Vimont DJ, Chiang JCH, Ji L, Seidel H, Tippett MK (2007) Pacific meridional mode and El NiñoSouthern Oscillation. Geophys Res Lett 34:L16608

Chen G, Plumb RA, Lu J (2010) Sensitivities of zonal mean atmospheric circulation to SST warming in an aqua-planet model. Geophys Res Lett 37:L12701

Chen SF, Yu B, Chen W (2014) An analysis on the physical process of the influence of AO on ENSO. Clim Dyn 42:973-989

Chiang JC, Vimont DJ (2004) Analogous Pacific and Atlantic meridional modes of tropical atmosphere-ocean variability. J Clim 17:4143-4158

Dee DP et al (2011) The ERA-Interim reanalysis: configuration and performance of the data assimilation system. Q J R Meteorol Soc 137:553-597

Ding QH, Steig EJ, Battisti DS, Wallace JM (2012) Influence of the tropics on the southern annular mode. J Clim 25:6330-6348

Ding RQ, Li JP, Tseng YH, Ruan CQ (2015a) Influence of the North Pacific Victoria mode on the Pacific ITCZ summer precipitation. J Geophys Res 120:964-979

Ding RQ, Li JP, Tseng YH (2015b) The impact of South Pacific extratropical forcing on ENSO and comparisons with the North Pacific. Clim Dyn 44:2017-2034

Ding RQ, Li JP, Tseng YH, Sun C, Xie F (2017) Joint impact of North and South Pacific extratropical atmospheric variability on the onset of ENSO events. J Geophys Res Atmos 122:279-298

Dou J, Wu Z (2018) Southern Hemisphere origins for interannual variations of snow cover over the Western Tibetan Plateau in boreal summer. J Clim 31:7701-7718

Dou J, Wu ZW, Zhou Y (2017) Potential impact of the May Southern Hemisphere annular mode on the Indian summer monsoon rainfall. Clim Dyn 49:1257-1269
Dou J, Wu ZW, Li J (2020) The strengthened relationship between the Yangtze River Valley summer rainfall and the Southern Hemisphere annular mode in recent decades. Clim Dyn 54:1607-1624

Fogt R, Bromwich D (2006) Decadal variability of the ENSO teleconnection to the high-latitude South Pacific governed by coupling with the southern annular mode. J Clim 19:979-997

Gill AE (1980) Some simple solutions for heat-induced tropical circulation. Q J R Meteorol Soc 106:447-462

Gollan G, Greatbatch RJ (2015) On the extratropical influence of variations of the upper-tropospheric equatorial zonal-mean zonal wind during boreal DJF. J Clim 28:168-185

Grassi B, Redaelli G, Visconti G (2005) Simulation of Polar Antarctic trends: influence of tropical SST. Geophys Res Lett 32:L23806

Hersbach H, Bell B, Berrisford P, Hirahara S, Horányi A, MuñozSabater J, Nicolas J et al (2020) The ERA5 global reanalysis. Q J R Meteorol Soc 146(730):1999-2049

Hong LC, Jin FF (2014) A southern hemisphere booster of super El Niño. Geophys Res Lett 41:2142-2149

Huang B, Thorne PW, Coauthors BVF et al (2017) Extended Reconstructed Sea Surface Temperature version 5 (ERSSTv5), Upgrades, validations, and intercomparisons. J Clim. https://doi. org/10.1175/JCLI-D-16-0836.1

Hurrell JW, Holland M, Gent P et al (2013) The community earth system model: a framework for collaborative research. Bull Am Meteorol Soc 94:1339-1360

Kalnay E et al (1996) The NCEP-NCAR 40-year reanalysis project. Bull Am Meteorol Soc 77:437-471

Kang SM, Held IM, Frierson DM, Zhao M (2008) The response of the ITCZ to extratropical thermal forcing: idealized slab-ocean experiments with a GCM. J Clim 21:3521-3532

Kwok R, Comiso JC (2002) Southern ocean climate and sea ice anomalies associated with the southern oscillation. J Clim 15:487-501

L'Heureux ML, Thompson DWJ (2006) Observed relationships between the El Niño Southern Oscillation and the extratropical zonal-mean circulation. J Clim 19:276-287

Lau NC (1997) Interactions between global SST anomalies and the midlatitude atmospheric circulation. Bull Am Meteorol Soc 78:1-13

Levine AFZ, McPhaden MJ, Frierson DMW (2017) The impact of the AMO on multidecadal ENSO variability. Geophys Res Lett 44:3877-3886

Li X, Holland DM, Gerber EP, Yoo C (2014) Impacts of the north and tropical Atlantic Ocean on the Antarctic Peninsula and sea ice. Nature 505:538-542

Li Y, Chen QL, Liu X, Li JP, Xing N, Xie F et al (2019) Long-term trend of the tropical Pacific trade winds under global warming and its causes. J Geophys Res Oceans 124:2626-2640

Liebmann B, Smith CA (1996) Description of a complete (interpolated) outgoing longwave radiation dataset. Bull Am Meteorol Soc 77:1275-1277

Liu ZY, Yang H (2003) Extratropical control of tropical climate, the atmospheric bridge and oceanic tunnel. Geophys Res Lett 30:1230

Liu T, Li JP, Zheng F (2015) Influence of the boreal autumn southern annular mode on DJF precipitation over land in the northern hemisphere. J Clim 28:8825-8839

Liu T, Li JP, Feng J, Wang XF, Li Y (2016) Cross-seasonal relationship between the boreal autumn SAM and winter precipitation in the northern hemisphere in CMIP5. J Clim 29:6617-6636

Liu T, Li JP, Li YJ, Zhao S, Zheng F, Zheng JY, Yao ZX (2018) Influence of the May southern annular mode on the South China Sea summer monsoon. Clim Dyn 51:4094-4107

Liu T, Li JP, Wang QY, Zhao S (2020) Influence of the autumn SST in the southern Pacific Ocean on winter precipitation in the North American monsoon region. Atmosphere 11(8):844

Marshall GJ (2003) Trends in the southern annular mode from observations and reanalyses. J Clim 16:4134-4143 
Marshall GJ, Connolley WM (2006) Effect of changing Southern Hemisphere winter sea surface temperatures on southern annular mode strength. Geophys Res Lett 33:L17717

Nan SL, Li JP (2003) The relationship between the summer precipitation in the Yangtze River valley and the boreal spring Southern Hemisphere annular mode. Geophys Res Lett 30:2266

Nan S, Li J, Yuan X, Zhao P (2009) Boreal spring southern hemisphere annular mode, Indian Ocean sea surface temperature, and East Asian summer monsoon. J Geophys Res. https://doi.org/10.1029/ 2008jd010045

Ribera P, Mann ME (2003) ENSO related variability in the Southern Hemisphere, 1948-2000. Geophys Res Lett 30:1006

Sallée JB, Speer KG, Rintoul SR (2010) Zonally asymmetric response of the Southern Ocean mixed-layer depth to the southern annular mode. Nat Geosci 3:273-279

Sen Gupta GA, England MH (2006) Coupled ocean-atmosphereice response to variations in the southern annular mode. J Clim 19:4457-4486

Terray P (2011) Southern Hemisphere extratropical forcing: a new paradigm for El Niño-Southern Oscillation. Clim Dyn 36:2171-2199

Thompson DWJ, Wallace JM (2000a) Annular modes in the extratropical circulation. Part I: month-to-month variability. J Clim 13:1000-1016

Thompson DWJ, Wallace JM (2000b) Annular modes in the extratropical circulation. Part I: trends. J Clim 13:1018-1036

Thompson DW, Solomon S, Kushner PJ, England MH, Grise KM, Karoly DJ (2011) Signatures of the Antarctic ozone hole in Southern Hemisphere surface climate change. Nat Geosci 4:741-749

Trenberth KE, Branstator GW, Karoly DJ, Kumar A, Lau NC, Ropelewski C (1998) Progress during TOGA in understanding and modeling global teleconnections associated with tropical sea surface temperatures. J Geophys Res 103:14291-14324

Trenberth KE, Stepaniak DP, Smith L (2005) Interannual variability of patterns of atmospheric mass distribution. J Clim 18:2812-2825

Tseng YH, Ding RQ, Huang XM (2017) The warm Blob in the northeast Pacific - the bridge leading to the 2015/16 El Niño. Environ Res Lett 12:054019

Vimont DJ, Battisti DS, Hirst AC (2001) Footprinting: a seasonal connection between the tropics and mid-latitudes. Geophys Res Lett 28:3923-3926

Vimont DJ, Wallace JM, Battisti DS (2003) The seasonal footprinting mechanism in the Pacific: implications for ENSO. J Clim 16:2668-2675

Wang SY, L'Heureux M, Chia HH (2012) ENSO prediction one year in advance using western North Pacific sea surface temperatures. Geophys Res Lett 3:L057029

Wu B, Zhou TJ (2013) Relationships between the East Asian-western north pacific monsoon an d ENSO simulated by FG0ALS-s2. Adv Atmos Sci 30:713-725
Wu ZW, Li JP, Wang B, Liu X (2009) Can the Southern Hemisphere annular mode affect China winter monsoon? J Geophys Res 114:D11107

Wu ZW, Dou J, Lin H (2015) Potential influence of the NovemberDecember Southern Hemisphere annular mode on the East Asian DJF precipitation: a new mechanism. Clim Dyn 44:1215-1226

Xing N, Li JP, Li YK (2014a) Response of the tropical atmosphere to isolated equatorial asymmetric heating. Chin Atmos Sci 38(6):1147-1158 (in Chinese)

Xing N, Li JP, Li YK (2014b) A theoretical explanation of anomalous atmospheric circulation associated with ENSO Modoki during boreal winter. Atmos Ocean Sci Lett 7:352-357

Xing N, Li JP, Jiang XW, Wang LN (2016) Local oceanic precursors for the summer monsoon onset over the bay of Bengal and the underlying processes. J Clim 29:8455-8470

Yamazaki K, Watanabe M (2015) Effects of extratropical warming on ENSO amplitudes in an ensemble of a coupled GCM. Clim Dyn 44:679-693

Yeo S-R, Kim K-Y (2015) Decadal changes in the Southern Hemisphere sea surface temperature in association with El NiñoSouthern Oscillation and Southern Annular Mode. Clim Dyn 45:3227-3242

Yuan XJ, Martinson DG (2000) Antarctic sea ice extent variability and its global connectivity. J Clim 13:1697-1717

Zhang L, Chang P, Ji L (2009a) Linking the Pacific meridional mode to ENSO: coupled model analysis. J Clim 22:3488-3505

Zhang L, Chang P, Tippett MK (2009b) Linking the Pacific meridional mode to ENSO: utilization of a noise filter. J Clim 22:905-922

Zhang H, Clement A, Nezio PD (2014) The south pacific meridional mode: a mechanism for ENSO-like variability. J Clim 27:769-783

Zhang YZ, Li JP, Xue JQ, Feng J, Wang QY, Xu YD et al (2018) Impact of the South China Sea summer monsoon on the Indian Ocean dipole. J Clim 31:6557-6573

Zheng F, Li JP, Wang L, Xie F, Li XF (2015) Cross-seasonal influence of the December-February Southern Hemisphere annular mode on March-May meridional circulation and precipitation. J Clim 28:6859-6881

Zheng F, Li JP, Ding RQ (2017) Influence of the preceding austral summer Southern Hemisphere annular mode on the amplitude of ENSO decay. Adv Atmos Sci 34:1358-1379

Zheng F, Li JP, Kucharski F, Ding RQ, Liu T (2018) Dominant SST mode in the southern hemisphere extratropics and its influence on atmospheric circulation. Adv Atmos Sci 35:881-895

Publisher's Note Springer Nature remains neutral with regard to jurisdictional claims in published maps and institutional affiliations. 